\title{
Colaboradores deste número
}

\author{
Pareceristas ad. hoc.
}

\section{AMARINO OLIVEIRA DE QUEIROZ}

Bacharel em Letras (Universidade Federal da Bahia). Mestre em Literatura e Diversidade Cultural (Universidade Estadual de Feira de Santana, Bahia). Doutor em Teoria da Literatura (Universidade Federal de Pernambuco) com tese sobre as Literaturas Africanas de Línguas Espanhola e Portuguesa. Atualmente é Professor Adjunto da Universidade Federal do Rio Grande do Norte, Departamento de Ciências Sociais e Humanas, campus de Currais Novos. Tem experiência nas áreas de Literaturas e Culturas Africanas, Literaturas e Culturas Hispânicas, Literatura e Cultura Brasileira, Teoria da Literatura, Literatura Portuguesa e Língua Espanhola. Na UFRN é membro da base de pesquisa Literatura e Sociedade (Regionalismos Literários). É também colaborador do grupo de pesquisa Literatura e Cultura Afro-brasileira e Africana de Língua Portuguesa, da Universidade Estadual da Paraíba, vinculado à linha Literaturas Africanas e da Diáspora.

\section{ANA CLÁUDIA ROMANO RIBEIRO}

Professora Adjunta na Pós-Graduação e na Graduação do Departamento de Letras da Escola de Filosofia, Letras e Ciências Humanas da Universidade Federal de São Paulo, na área de Língua e Literatura Francesa, graduada em Letras (Universidade Federal de Juiz de Fora) e Etnologia (opção 
Etnomusicologia, Université Paris X - Nanterre), Ana Cláudia Romano Ribeiro fez mestrado e doutorado (este, com bolsa FAPESP) pelo programa de pós-graduação em Teoria e História Literária da Universidade Estadual de Campinas, tendo realizado estágio doutoral na Università degli Studi di Firenze (com apoio da CAPES). Parte de sua pesquisa foi publicada em A terra austral conhecida (Genebra, 1676), de Gabriel de Foigny (Tradução, apresentação e notas. Campinas: Editora da UNICAMP, 2011). Foi junior visiting scholar na Università degli Studi di Milano (Itália), com uma bolsa da Fondazione CARIPLO (Progetto UniALA). É Pesquisadora Colaboradora na área de Estudos Clássicos do Instituto de Estudos da Linguagem, na Universidade Estadual de Campinas, onde foi bolsista do CNPq e desenvolve seu atual projeto de pós-doutorado, que tem por objeto a Utopia, de Thomas More (tradução e estudo). É pesquisadora nos grupos Renascimento e Utopia (CNPq/UNICAMP), U-TOPOS - Centro de Pesquisa sobre Utopia (UNICAMP) e Intertextualidade na literatura latina: teorias e práticas intertextuais na literatura latina e sua recepção (CNPq/UNICAMP). Co-edita a revista acadêmica anual Morus - Utopia e Renascimento e co-organiza os eventos científicos e publicações ligados a este periódico. Seus temas de pesquisa são: tradução; viagens imaginárias, utopias e distopias; literatura e filosofia nos séculos XVI e XVII francês; literatura e história; literatura neolatina dos séculos XVI e XVII; tradição clássica; recepção; relação entre literatura e outras.

\section{CARMEN VERÔNICA DE ALMEIDA RIBEIRO NÓBREGA}

Doutora em Estudos da Tradução pela Universidade Federal de Santa Catarina - UFSC, Mestrado em Educação pela Universidade Federal da Paraíba - UFPB (2006), Graduação em LICENCIATURA PLENA EM LETRAS, habilitação em Língua e Literatura Francesas, pela Universidade Regional do Nordeste (1983). Atualmente é professora de Língua Francesa, da Universidade Federal de Campina Grande - UFCG.

\section{CLEYDSTONE CHAVES}


Possui graduação em Letras Estrangeiras Modernas Inglês pela UFPB (1999), Francês pela UFCG (2004), mestrado em Letras pela UFPB (2006) e doutorado em Estudos da Tradução pela UFSC (2014). Também tem formação linguística em alemão e espanhol pela UFCG. E alemão Fernstudium (UFBA-Goethe Institut). Atualmente é Professor Adjunto I, Iotado na Unidade Acadêmica de Letras - UAL na UFCG. Tem experiência na área de Letras com ênfase em linguística aplicada, atuando nos seguintes temas: novas tecnologias no processo ensino-aprendizagem de língua estrangeira sob uma perspectiva sociocultural; e o papel da língua materna no processo ensino-aprendizagem de língua estrangeira. Também é pesquisador em Estudos da Tradução/Tradução Automática (TA) focando em pontos que dialogam a TA com os seguintes eixos temáticos: Linguagem controlada no texto fonte; Comparação com Sistemas de TA; Comparação com Tradução Humana; e Aplicações no Ensino de Línguas Estrangeiras.

\section{FRANCINE FERNANDES WEISS RICIERI}

Licenciada em Letras pela Universidade Estadual de Londrina (1988), mestrado em Teoria Literária e Literatura Comparada pela Universidade Estadual Paulista Júlio de Mesquita Filho / UNESP (1996), doutorado em Teoria e História Literária na área de Literatura Brasileira pela Universidade Estadual de Campinas / UNICAMP (2001) e pós-doutorado em Literatura Brasileira pela UNICAMP (FAPESP). Tem experiência na área de Letras, com ênfase em Literatura Brasileira e Literatura Portuguesa, atuando principalmente nos seguintes temas: Alphonsus de Guimaraens, simbolismo e decadentismo, relações entre Brasil, Portugal e França em poetas oitocentistas. Atua como professora de Literatura Brasileira na Universidade Federal de São Paulo (UNIFESP), Campus Guarulhos. Atualmente desenvolve projeto sobre poesia narrativa contemporânea. Credenciada no Programa de Mestrado da UNIFESP/ Guarulhos. 
Graduado em Letras - Francês e Português - pela Universidade de São Paulo. Fez mestrado em língua e literatura francesa na Universidade de São Paulo, tendo analisado a constituição irônica e seu papel argumentativo em gêneros da imprensa quotidiana, em publicações brasileiras e francesas. Na tese de doutoramento, também concluída na Universidade de São Paulo, continuou estudando a problemática da argumentação em textos de imprensa, com ênfase na análise dos textos de divulgação/vulgarização científica. Tem experiência como professor de língua portuguesa e de língua francesa, no ensino básico e superior, com mais de dez anos de atuação em escolas públicas e privadas de São Paulo. Desenvolveu trabalhos de assessoria e consultoria na área de língua portuguesa e na produção de livros e manuais didáticos. Autor de várias obras voltadas para o ensino de língua portuguesa. Atualmente é Professor Adjunto da Escola de Filosofia, Letras e Ciências Humanas da Universidade Federal de São Paulo (Unifesp).

\section{LUCIENE MARIA PATRIOTA}

Possui Graduação em Licenciatura Plena em Letras pela Universidade Federal da Paraíba (1993), Especialização em Linguística Aplicada ao Ensino pela Universidade Federal de Campina Grande (2002), Mestrado em Linguagem e Ensino pela Universidade Federal de Campina Grande (2006) e Doutorado em Linguística pela Universidade Federal da Paraíba (2011). Tem experiência na área de Letras, com ênfase em Letras, atuando principalmente nos seguintes temas: gíria, livro didático, ensino e língua. Professora Adjunta da UFCG (2013). Atualmente coordena o Programa de Monitoria da Unidade Acadêmica de Letras (UFCG).

\section{LUÍS FERNANDO PRADO TELLES}

Professor de Teoria Literária da Escola de Filosofia, Letras e Ciências Humanas da Universidade Federal de São Paulo (UNIFESP). Possui bacharelado e licenciatura em Letras (1997), mestrado (2000) e doutorado (2009) em Teoria e 
História Literária pela Universidade Estadual de Campinas (UNICAMP). Desenvolveu pesquisa de Pós-Doutorado junto ao Departamento de Letras Clássicas e Vernáculas da Universidade de São Paulo (USP) durante os anos de 2013 e 2014. Tem experiência de ensino e pesquisa nas áreas de Letras, atuando, principalmente, nos seguintes temas: teoria da literatura, teoria do romance, teoria da narrativa, narrativa contemporânea em literaturas de língua portuguesa.

\section{MARIA DEL CARMEN DE LA TORRE ARANDA}

Possui Bacharelado e Licenciatura em Ciências Sociais pela Universidade Estadual de Campinas (1986), Especialização em Tradução Francês-Português pela Universidade de São Paulo (2004), Mestrado Erasmus Mundus em Engenharia de Mídias para a Educação (EUROMIME) pelo consórcio que reúne a Universidade Técnica de Lisboa, Portugal, a Universidad Nacional de Educación a Distancia de Madrid, Espanha, e a Université de Poitiers, França (2009), e Doutorado em Letras (Estudos Linguísticos, Literários e Tradutológicos em Francês) pela Universidade de São Paulo (2011). Atualmente, é professora adjunta da área de Língua Francesa e respectiva Literatura no Departamento de Línguas Estrangeiras e Tradução (LET) da Universidade de Brasília (UnB) e atua, portanto, na área de ensino de língua estrangeira e formação de professores de línguas. Suas áreas de interesse em pesquisa são o desenvolvimento da oralidade em língua estrangeira, o uso de tecnologias digitais nos processos de ensino e aprendizagem de línguas, e os processos de interação e de mediação humana e tecnológica nesses meios.

\section{MÔNICA FIÚZA BENTO DE FARIA}

Possui mestrado em Letras (Literaturas francófonas) pela Universidade Federal Fluminense - UFF (1997) e doutorado em Letras (Estudos Linguísticos) pela Universidade Federal Fluminense - UFF (2003). Atualmente é Professora de francês 
do Departamento de Línguas e Literaturas estrangeiras Modernas da Universidade Federal do Rio Grande do Norte - UFRN e Universidade Federal Fluminense - UFF Foi coordenadora e professora de Francês do Liceu Franco-Brasileiro (Rio de Janeiro), professora do Colégio de Aplicação PUC-RIO, coordenadora pedagógica e professora da Aliança Francesa Rio e Diretora de filial da Aliança Francesa Rio. É membro da diretoria da Associação Cultural Franco Brasileira de Natal Aliança Francesa de Natal e Formadora (CIEP-França) de corretores e examinadores do DELF \& DALF. Atua na graduação na área de Letras, com interesse nas seguintes áreas: ensino aprendizado do Francês Língua Estrangeira, avaliação, tradução, FOS.

\section{MARIA LUIZA BATISTA}

Professora da Universidade Federal da Paraíba (UFPB). Doutora em Letras pela Universidad Nacional de Buenos Aires (UBA). Mestra em Letras pela Universidade Federal da Paraíba (UFPB). Graduada em Letras pela Universidade Federal da Paraíba (UFPB). Atua nas áreas de Inglês, Espanhol e Literatura Hispano-americana.

\section{RENATA PHILIPPOV}

Possui bacharelado em Letras (Português/Inglês/Francês) pela Universidade de São Paulo (1994), licenciatura em Letras (Português/Inglês/Francês) pela Universidade de São Paulo (1995), mestrado em Letras (Língua e Literatura Francesa) pela Universidade de São Paulo (1999), doutorado em Letras pela Universidade de São Paulo (2005) e pós-doutorado em Linguística Aplicada pelo LAEL/PUCSP (2015). Tem experiência na área de Letras, com ênfase em Línguas e Literaturas Estrangeiras Modernas, atuando principalmente nos seguintes temas: língua inglesa, literaturas de língua inglesa, metodologia de ensino, formação docente, gestão curricular integrada, Edgar Allan Poe, Charles Baudelaire, 
Machado de Assis, estudos de recepção literária e literatura comparada. Atualmente desenvolve projeto de pesquisa sobre a recepção crítica da obra de Edgar Allan Poe na obra de Machado de Assis, pelo viés da literatura fantástica. É credenciada no Programa de Mestrado em Letras da UNIFESP-campus Guarulhos. É membro do GT Vertentes do Insólito Ficcional da Anpoll e líder do grupo de pesquisa Língua e Literatura: interdisciplinaridade e docência (CNPq).

\section{SELMA ALAS MARTINS}

Pós-doutorado em Ciências da Educação pela Université de Lyon2 (2010), Doutorado em Educação pela Universidade de São Paulo (2003), Mestrado em Educação pela Universidade Federal do Rio Grande do Norte (1997), Especialização em Linguística Textual pela Universidade Federal do Rio Grande do Norte (1988) e Graduação em Letras, habilitação Português-Francês, pela Universidade Católica de Santos (1979). Atualmente é professora da área de Língua Francesa e do Programa de Pós-Graduação em Estudos da Linguagem, na Universidade Federal do Rio Grande do Norte. Tem experiência na área de Linguística Aplicada ao Ensino de Língua Estrangeira, atuando principalmente nos seguintes temas: metodologia do ensino, formação de professores, compreensão leitora, intercompreensão de línguas românicas, tecnologias e 0 ensino de línguas.

\section{VALTER CÉSAR PINHEIRO}

Possui graduação em Letras pela Universidade de São Paulo, com licenciatura em português e em francês (1995), mestrado em Letras (Língua e Literatura Francesa) pela Universidade de São Paulo (2005) e doutorado em Letras (Estudos Linguísticos, Literários e Tradutológicos em Francês) pela Universidade de 
São Paulo (2014). Atualmente é professor de literatura francesa no Departamento de Letras Estrangeiras da Universidade Federal de Sergipe. Foi professor da Aliança Francesa de São Paulo (19952008) e do Colégio Palmares (1999-2012). Tem experiência na área de Letras, com ênfase em literatura francesa, atuando principalmente nos seguintes temas: relações Brasil-França, literatura francesa, literatura brasileira e literatura comparada. 


\section{REVISORES COLABORADORES DESTE NÚMERO:}

Déborah Alves Miranda

Laryssa Barros de Araújo

José Ribamar Carolino Bezerra

Nathália Niely Tavares Alves

Suênio Stevenson Tomaz da Silva 